\title{
Universidade Aberta da Terceira Idade da PUCRS
}

\author{
Mirna Wetters Portuguez', Newton Luiz Terra²

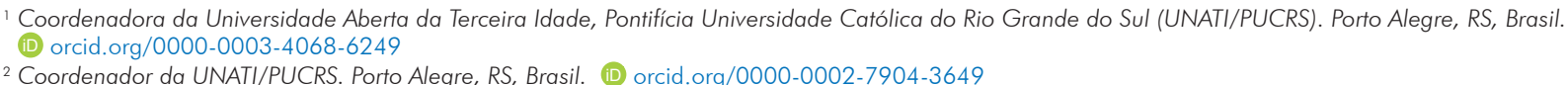 \\ 2 Coordenador da UNATI/PUCRS. Porto Alegre, RS, Brasil. (D) orcid.org/0000-0002-7904-3649
}

\begin{abstract}
És do conhecimento de muitos que há uma evidente relação entre qualidade de vida de uma determinada sociedade e a excelência das suas universidades. Propostas e ações que promovam o bem-estar social originam-se da união de esforços da comunidade universitária. Esse é o caso da Pontifícia Universidade Católica do Rio Grande do Sul (PUCRS). A Universidade procura oferecer soluções para transformar a sociedade e influenciar positivamente o futuro das pessoas, contribuindo para o crescimento do estado do Rio Grande do Sul. O avanço do conhecimento e o contínuo progressivo aperfeiçoamento das práticas e dos empreendimentos de caráter educativo, formativo e de assistência à saúde são um constante desafio para assegurar uma maior responsabilidade social e um compromisso solidário adequado ao tempo presente.

A PUCRS tem o compromisso de colaborar para um futuro melhor para todos pautado pela justiça e pelo respeito. $\mathrm{O}$ crescimento da população idosa brasileira é uma realidade e está ocorrendo em um nível sem precedentes. Em 2025, o Brasil ocupará a sexta colocação em número de idosos no mundo e será ultrapassado somente por China, Índia, Rússia, Estados Unidos e Japão. Nesse ano, a população acima de 60 anos será superior a 32 milhões de habitantes. $\mathrm{O}$ Rio Grande do Sul está envelhecendo mais rapidamente que a média nacional. Em 2030, o estado do Rio Grande do Sul terá uma taxa maior de mortes que nascimentos e, consequentemente, um envelhecimento mais acelerado. Segundo dados do IBGE, 19\% da população gaúcha tem mais que 60 anos, o que corresponde a cerca de 2 milhões de indivíduos. A expectativa de vida do ser humano cresce no Brasil e em quase todo o planeta. Há um século, o brasileiro vivia em média 40 anos. Hoje, vive aproximadamente 77. Projeções para 2060 indicam que no Rio Grande do Sul a expectativa de vida será de mais ou menos 84 anos. Os homens deverão atingir os 80,94 anos, e as mulheres, 86,90.

Uma das preocupações da Geriatria e da Gerontologia é também o prolongamento da vida saudável e digna. Existe uma preocupação mundial para que as pessoas consigam um envelhecimento ativo, isto é, saudável, participativo, seguro, produtivo, com autonomia e independência, para que envelheçam com alegria, com entusiasmo e vitalidade para continuar aprendendo e descobrindo coisas novas. Embora existam mitos e preconceitos que estigmatizam os idosos como incapazes de aprender, uma nova consciência está surgindo em relação à integração dos idosos na sociedade.
\end{abstract}


É importante frisar que os idosos possuem a conhecida inteligência cristalizada, que se relaciona com as experiências pessoais, com o meio ambiente e com a realidade social. Não declina com o envelhecimento e pode apresentar progressos, desde que existam oportunidades. Refere-se a conhecimentos gerais e específicos, solução de problemas do cotidiano, conteúdos escolares e competência linguística e tende a manter-se ou elevar-se com a idade.

Consciente do impacto do envelhecimento populacional no Rio Grande do Sul, a PUCRS criou a Universidade Aberta da Terceira Idade (UNATI), com o objetivo de contribuir para a melhoria da qualidade de vida das pessoas em processo de envelhecimento, oferecendo orientação e serviços de saúde específicos. Trata-se de um programa de educação não formal de caráter permanente destinado às pessoas em processo de envelhecimento que oportuniza aprendizagem de conteúdos, valores e atitudes, bem como formas de saber, de adquirir, de usar e de aplicar esses conhecimentos em diferentes situações do cotidiano. Essas aprendizagens promovem capacidades e habilidades que o indivíduo em processo de envelhecimento necessita para se desenvolver e se manter como cidadão. Procura fazer com que o idoso assimile conhecimentos e atinja um novo patamar, ampliando sua visão de mundo e suas possibilidades de inserção.

Seus grandes objetivos são possibilitar às pessoas o acesso à Universidade, como meio de ampliação do espaço cultural, bem como a educação continuada, pelo oferecimento de cursos e atividades que propiciem a atualização de conhecimentos. Visa ainda oferecer à população que envelhece a prática de atividades que possibilitem fortalecer sua participação social e política, com vistas a assumir o seu processo de envelhecimento e gozar do pleno exercício da sua cidadania.

As pessoas em processo de envelhecimento são o público-alvo desse Programa, que tem como metas: auxiliar no desenvolvimento de novas capacidades; oportunizar o reingresso num processo de formação continuada em cursos variados por meio de atividades educacionais, culturais e sociais; contribuir para a melhoria de sua qualidade de vida e para que se tornem saudáveis, produtivas, úteis e participativas na comunidade; contribuir para que aprendam e descubram novos interesses motivadores, novos propósitos e que realizem projetos de vida; proporcionar espaço gerador de convivência e troca de experiências; contribuir para que se mantenham social e intelectualmente ativos; colaborar para que se mantenham ou retornem para o mercado de trabalho; proporcionar informações que permitam reflexões sobre a senescência e que os auxiliem na promoção e transformações sociais que possam ser úteis na conquista de uma velhice bem-sucedida; estimular sua participação em processo de envelhecimento nas atividades sociais, políticas, econômicas e culturais da sua comunidade.

A UNATI/PUCRS pretende ainda evitar que as expressões "idoso" ou "velho" estejam associadas à ideia de decadência, de incapacidade para o trabalho e de exclusão social. Muito pelo contrário, foi criada para proporcionar aos idosos a continuidade de uma vida ativa, independente, produtiva e prazerosa, a fim de que tenham uma velhice mais saudável, com novos projetos de vida, mais satisfeitos e mais felizes. 